\title{
EL COMMENTAIRE PHILOSOPHIQUE DE PIERRE BAYLE.
}

"Dios no quiere que conozcamos con certeza"

\section{Fernando Bahr CONICET}

Pierre Bayle tenía treinta y ocho años cuando en 1686 dio a conocer las dos primeras partes de su Commentaire philosophique sur ces paroles de Jésus-Christ 'Contrain-les d'entrer' ${ }^{1}$. El escrito apareció como una supuesta traducción francesa -hecha por "M. J. F"- de la obra en inglés de un "erudito presbiteriano" llamado Jean Fox de Bruggs ${ }^{2}$ y como lugar de impresión se indicaba, falsamente, "Thomas Litwell, de Canterbury" ${ }^{3}$. Su publicación había sido anunciada en dos oportunidades (marzo y agosto de 1686) por las Nouvelles de la République des Lettres que editaba el propio Bayle. Estas referencias, sumadas a las reseñas muy críticas que algunas apologías de la intolerancia civil habían recibido en diversos números de las Nouvelles $^{4}$ y a la inocultable semejanza que existía entre ciertos pasajes del comentario y, por ejemplo, los argumentos esgrimidos un año atrás en las Nouvelles lettres de l'auteur de la Critique générale de l'Histoire du calvinisme de Mr. Maimbourg, obra que Bayle reconocía como propia, hicieron que pronto se develara el secreto acerca de su autoría ${ }^{5}$.

\footnotetext{
${ }^{1}$ El título completo del escrito es Commentaire philosophique sur ces paroles de Jésus-Christ CONTRAIN-LES D'ENTRER; Où l'on prouve, par plusieurs raisons démonstratives $Q u^{\prime} i l$ n'y a rien de plus abominable que de faire des Conversions par la Contrainte: Et où l'on réfute Tous les Sophismes des Convertisseurs à contrainte, et l'Apologie que St. AUGLSTIN a faite des Persécutions.

${ }_{2}^{2}$ Gianluca Mori (Introduzione a Bayle, Bari-Roma, Laterza, 1996, pp. 63) conjetura que ese pseudónimo podría apuntar un homenaje conjunto a dos protestantes herejes del pasado que habían defendido vigorosamente la tolerancia: el cuáquero George Fox y al anabaptista David Joris, cuyo pseudónimo era Jean de Bruggs.

${ }^{3}$ En realidad, la impresión estuvo a cargo de Wolfgang y se hizo en Amsterdam.

+ Véase Pierre Bayle, Nouvelles de la République des Lettres (en adelante NRL), Oeuvres diverses (en adelante OD), edición de E. Labrousse, Hildesheim, Georg Olms, 1964-82, tomo I, pp. 359 a. $385-87,523$ a, 629 a y $698-99$.

${ }^{5}$ Bayle, de todas maneras, jamás admitió explícitamente que fuera el autor del Commentaire. Pierre Jurieu, su más encarnizado enemigo, atribuyó el escrito en principio a "una cábala de varios teólogos
} 
El cometido del escrito es atacar los fundamentos teológicos y morales de la persecución religiosa, de las multas y condenas a prisión, del derrumbe de los templos y los bautismos coactivos, que los obispos franceses denominaban "violencia caritativa y salvífica que se hace a los herejes para retirarlos de sus extravíos". Organiza su ofensiva en tres partes bien diferenciadas. La primera se ocupa de reunir argumentos que refuten una interpretación ad litteram del "oblígalos a entrar" pronunciado por Jesucristo en la parábola del banquete (Evangelio según san Lucas, XIV, 23), expresión que era casi un lugar común de la teología cristiana para justificar el uso de la violencia. La segunda procura responder a las objeciones que se habían propuesto o podrían proponerse a los argumentos de la primera parte. La tercera se dedica a refutar los pasajes de las cartas de san Agustín en los se justificaba el empleo de los poderes seculares para extirpar la herejía donatista ${ }^{6}$. En el presente artículo haremos escasas alusiones a esta última sección; en ella, de todas maneras, Bayle no hace más que aplicar a un caso concreto, aunque muy prestigioso, los argumentos que había desarrollado con anterioridad de forma más general. Nos concentraremos, pues, en las dos primeras partes, y nuestro propósito es tanto dar a conocer el escrito (uno de los más importantes en la historia moderna de la tolerancia) como indagar en algunas de las tensiones que se observan en él y que hacen del Commentaire un compuesto enigmático.

\section{1. "El más racionalista y cristiano de sus escritos".}

Bayle inicia su comentario elaborando varios argumentos para demostrar que las palabras de Jesucristo en la parábola del banquete no podrían dar legitimidad al empleo de la violencia contra los supuestos herejes. Esos argumentos, nueve en total e inde-

refugiados", pero sin dudar de que Bayle fuera, por lo menos, uno y el más importante de los intrigantes. Véase al respecto E. Labrousse, Pierre Bayle, tomo I, Dordrecht, Martinus Nijhoff, 2 da. edición, 1985, p. 214, n. 39.

${ }^{6}$ Esos pasajes habían sido rescatados en 1685 por Philippe Dubois-Goibaud en su Conformité de la conduite de l'Eglise de France pour ramener les Protestants: avec celle de l'Eglise d'Afrique, pour ramener les Donatistes à l'Église catholique. 
pendientes entre sí, comparten la condición de "filosóficos", esto es, se apoyan sobre "principios más generales e infalibles que todos los que podrían proveer el estudio de las lenguas, de la crítica y de los tópicos" ${ }^{7}$. Quieren situarse, así, fuera de las discusiones confesionales, "bajo una imagen de universalidad", y oponer a la coacción religiosa algo más sólido que las siempre discutibles interpretaciones bíblicas propuestas por los hermeneutas: "los axiomas de la metafísica", "la idea natural de equidad" o las máximas del sentido común.

Pasar revista aquí a todos esos argumentos resultaría imposible. Nos referiremos al más importante de ellos, expuesto en el Capítulo I. Allí se afirma como un principio de la luz natural "que todo sentido literal que contenga la obligación de cometer crímenes es falso", o, más explícitamente, que si por una interpretación literal de la Escritura "se compromete al hombre a cometer crimenes, o (para evitar cualquier equívoco) a cometer acciones que la luz natural, los preceptos del decálogo y la moral del Evangelio nos prohiben, se debe tener la plena seguridad de que le damos un sentido falso, y que, en lugar de la revelación divina, proponemos al pueblo sus propias visiones, sus pasiones y sus prejuicios" ${ }^{8}$. Bayle sostiene a continuación que entre los preceptos del decálogo, la moral del Evangelio y los conocimientos de la luz natural no puede haber desacuerdo, puesto que desde Adán, "la verdad revelada ha estado como sometida a la luz natural, para recibir de ella su atractivo, su sello, su registro y su verificación, y el derecho a obligar a título de ley"9. Más aún, las leyes de lo honesto y de lo equita-

\footnotetext{
${ }^{7}$ Comm. Phil., I, i, OD, II, p. 367a.

${ }^{8}$ Comm. Phil., I, i, OD, II, p. 367 a-b. Bayle atribuye esta regla de interpretación de la Escritura a san Agustín: "Jesucristo, dice él (De doctrina christiana, 3, 1), declara que si no comemos la carne del hijo del hombre no seremos salvados; parece que eso significaría ordenarnos un crimen, es por lo tanto una figura que nos lleva a contagiarnos de la pasión del Señor y a grabar agradable y útilmente en la memoria que su carne ha sido crucificada y lastimada por nosotros". Estas palabras de Agustín habían sido utilizadas desde siempre por los calvinistas para refutar la interpretación literal (católica) del Hoc est corpus meum pronunciado por Jesucristo en la última cena (véase al respecto Walter Rex, Essays on Pierre Bayle and Religious Controversy, The Hague Martinus Nijhoff, 1965, p. 156).

${ }^{9}$ Comm. Phil., I, i, OD, II, p. 369a.
} 
tivo, leyes que están impresas en el alma de todos los hombres y resultan transparentes para la razón atenta, leyes a las que incluso la soberana Razón debe atenerse, constituyen la revelación original de Dios y definen nuestra religión natural ${ }^{10}$. Esa condición hace que tanto el Antiguo como el Nuevo Testamento valgan en la medida en que hayan sido convalidados por las mismas; de manera que si Moisés o Jesucristo hubieran ordenado emplear la violencia para convertir a todos los que no quisieran hacerlo voluntariamente, nuestra razón y nuestra religión natural "tendrían motivos para entrar en grandes desconfianzas" y para considerarlos como emisarios del Demonio antes que enviados del verdadero Dios ${ }^{11}$. No lo han hecho. Las leyes mosaicas pasaron con holgura su prueba frente al tribunal de la razón y el mensaje evangélico ha fortificado y perfeccionado nuestra religión natural, pero son esos acuerdos los que legitiman la misión de Moisés o certifican la divinidad de Jesucristo, no sus milagros y prodigios ${ }^{12}$.

Como es visible, en este primer capítulo Bayle adopta una posición estrictamente racionalista frente al texto bíblico, posición que sólo se distingue de las sostenida por Socin y sus seguidores en la medida en que quiere limitarse al dominio moral sin avanzar sobre los dogmas especulativos ${ }^{13}$. Los conceptos que utiliza, y que

\footnotetext{
11 "Estoy convencido de que antes de que Dios le hubiera hecho escuchar alguna voz a Adán para enseñarle lo que debía hacer, ya le había hablado interiormente, haciéndole ver la idea vasta e inmensa del Ser soberanamente perfecto y las leyes eternas de lo honesto y de lo equitativo; de manera que Adán no se creyó obligado a obedecer a Dios tanto a causa de que una cierta prohibición había alcanzado sus oídos como a causa de que la luz interior que lo había esclarecido, antes de que Dios hubiera hablado, continuaba presentándole la idea de su deber y su dependencia del Ser supremo" (Comm. Phil., I, i, OD, II, pp. 369a). Véase también p. 368a-b y p. 371a.

${ }^{11}$ Véase Comm. Phil., I, iii, y I, iv, OD, II, pp. 373a, 374b y 376b.

12 Véase Comm. Phil. I, i, y I, iii, OD, II, pp. 369 a, 369b, 370a, 373a y 374b.

13 "A Dios no le gusta que yo extienda la jurisdicción de la luz natural y de los principios metafísicos tanto como los socinianos, que pretenden que todo sentido dado a la Escritura que no sea conforme con esta luz y con esos principios debe ser rechazado, y que en virtud de la máxima se niegan a creer en la Trinidad y en la Encarnación. No, no, yo no pretendo algo carente de límites y topes. [...] Lo repito una vez más. A Dios no le gusta que yo entienda este principio tanto como los socinianos; pero si puede tener ciertas limitaciones en relación con las verdades especulativas, no pienso que deba tener alguna en relación con los principios prácticos y generales que se refieren a las costumbres. Quiero decir que, sin excepción, es preciso someter todas las leyes morales a esta idea natural de equidad, la cual, al igual que la luz metafísica, ilumina a todo hombre que viene al mundo" (Comm.
} 
utilizará en los tres capítulos siguientes, remiten a la escuela cartesiana, y especialmente a Malebranche: la filosofía verdadera como "señora" entre las ciencias ${ }^{14}$, la atención como plegaria natural de la inteligencia, Dios como luz del mundo que habla interiormente a todos los hombres, incluso Dios como "lugar" en que vemos las ideas $^{15}$, Se ha mostrado, asimismo, que muchos argumentos de estos capítulos manifiestan en forma explícita ideas ya presentes en los criterios exegéticos elaborados por la escuela calvinista de Saumur, criterios que habían servido a autores como Moïse Amyraut para reclamar la tolerancia de los reformados en Francia ${ }^{16}$. La exégesis racionalista de las Escrituras no es por lo tanto una nove-

Phil., I, i, OD, II, pp. 367b).

14 "Todos los teólogos, de cualquier facción que sean -dice Bayle-, después de haber realzado tanto como les plugo la revelación, el mérito de la fe y la profundidad de los misterios, vienen a hacer un homenaje con todo eso a los pies del trono de la razón, y reconocen, aunque no lo digan con palabras (pero su conducta es un lenguaje bastante expresivo y elocuente), que el tribunal supremo y que juzga en última instancia y sin apelación todo lo que nos es propuesto, es la razón a través de los axiomas de la luz natural o de la metafísica. Que no se nos diga más, pues que la teología es una reina de la cual la filosofía no es más que una sierva, porque los teólogos mismos testimonian con su conducta que consideran a la filosofía como la reina y a la teología como la sierva" (Comm. Phil., I, 1, OD, II, p. 368a). Walter Rex, quien ha considerado este pasaje como "un punto de inflexión en la historia intelectual de Francia en el siglo XVII, acaso sólo superado en importancia por el Discurso del método", lo compara acertadamente con el siguiente párrafo del Traité de morale de Malebranche: "'Pero, se nos dice, la razón está corrompida: está sometida al error, hace falta que sea sumisa a la fe. La filosofía no es más que la sierva. Es preciso desconfiar de sus luces.' Equívocos perennes. El hombre no es su propia luz. La verdadera filosofia es la religión. No la filosofía de los paganos, lo reconozco, ni la de los charlatanes que dicen lo que no han concebido, que hablan a los otros antes de que la Verdad les haya hablado. La razón es infalible, inmóvil, incorruptible. Debe ser siempre señora: Dios mismo la sigue [...]"(pp. 20 de la edición de Henri Joly, Paris, J. Vrin, 1953. Citado en W. Rex, Essays on Pierre Bayle and Religious Controversy, p. 154). Recordemos que el Traité de morale había sido publicado en 1684 y recibió una reseña muy elogiosa en las Nouvelles de la République des lettres (OD, I, pp. 104b-106b). Se encontrarán reflexiones muy interesantes sobre la relación Bayle-Malebranche en Gianni Paganini, Analisi della fede e critica della ragione nella filosofia di Pierre Bayle, Firenze, La Nuova Italia Editrice, 1980, pp. 57-74.

${ }^{15}$ Obsérvese este pasaje: "Si buscamos la verdadera razón de esto (de la necesidad de una homologación racional) no podemos dejar de encontrarla; es que habiendo una luz viva y distinta que esclarece a todos los hombres tan pronto como abren los ojos de su atención, y que los convence invenciblemente de su verdad, hace falta concluir de allí que es Dios mismo, la Verdad esencial y sustancial, quien nos esclarece inmediatamente, pues, y quien nos hace contemplar en su esencia las ideas de las verdades eternas, contenidas en los principios o en las nociones comunes de la metafísica" (Comm. Phil., I, i, OD, II, pp. 368. Cursivas nuestras).

${ }^{16}$ Sobre la teología de Saumur y su relación con el Commentaire, se encontrarán análisis muy interesantes en W. Rex, Essays on Pierre Bayle and Religious Controversy, Cap. V, y en F. Laplanche, L'Écriture, le sacré et l'histoire, Cap. XIII, especialmente pp. 660-667. 
dad introducida por el Commentaire; tampoco lo es su recusación de la violencia en cuanto profanación del "camino interior" que lleva a la verdad. Lo novedoso aquí es, como decíamos antes, que los criterios racionalistas ya no estén al servicio de una reivindicación confesional. Bayle se dirige a todos los hombres de buena fe y refuerza esa apertura universal reemplazando los términos "católicos" y "calvinistas" por los términos "ortodoxos" y "herejes": un simple cambio de lenguaje que le permite, por un lado, extender su crítica a todas las situaciones violentas, sean cuales fueren el credo perseguidor y el credo perseguido, $\mathrm{y}$, por el otro, marcar los vínculos existentes entre razón filosófica y sociedad pluriconfesional ${ }^{17}$. He allí un punto que los teólogos de Saumur difícilmente habrían admitido ${ }^{18}$. De todas maneras, queda claro a lo largo de los capítulos inicales del Commentaire que la verdad religiosa tiene un carácter objetivamente determinable y que la misma recusa de manera concluyente el uso de la fuerza.

El bloque racionalista del Commentaire aparece hasta aquí, por lo tanto, sin fisuras, y resultaría muy difícil encontrar motivos suficientes para discutirle a Elisabeth Labrousse su calificación de esta obra como "a la vez la más cristiana y la más racionalista" de las concebidas por Pierre Bayle ${ }^{19}$. En el Capítulo IV de la primera parte, no obstante, se argumenta que "los derechos de la conciencia son directamente los del mismo Dios" y que, por lo tanto, "el orden necesario e inmutable quiere que se alejen, tanto como se pueda, todas las circunstancias que pongan al hombre en una ocasión próxima y en un peligro casi inevitable de traicionar su conciencia

\footnotetext{
${ }^{17} \mathrm{Rex}, \mathrm{W}$ (Essays on Pierre Bayle and Religious Controversy; pp. 176) observa que mediante ese cambio Bayle va mucho más allá del Edicto de Nantes. Este edicto, al legitimar el calvinismo, proyectaba a Francia como un Estado biconfesional; Bayle, en cambio, piensa en un Estado concebido como reunión de confesiones diversas.

${ }^{18}$ Laplanche (L'Écriture, le sacré, l'histoire, pp. 667) observa que Amyraut, por ejemplo, admitía que el príncipe pudiera ahogar una secta herética en su nacimiento, pero no cuando el nuevo grupo hubiera tomado cuerpo y afirmado su existencia. Bayle rechaza de manera explícita esta idea en Comm. Phil., II, vii, OD, II, p. 422a.

1" Labrousse, E., "Bayle et le deux Antiquités". en Conscience et conviction. Études sur le XVIle. siècle, Paris, Universitas, Oxford, Voltaire Foundation, 1996, p. 147.
} 
y su Dios" ${ }^{20}$. Está claro que este tema, el de la libertad de la conciencia, constituyó uno de los recursos más caros a la teología reformada de los siglos XVI y XVII: el propio Calvino había calificado a la conciencia como "un santuario inviolable" para las leyes humanas y sometido solamente a la ley de Dios ${ }^{21}$. Para él, empero, como para toda la ortodoxia posterior, esa libertad era libertad para la verdad cristiana, no aquella libertad que Teodoro de Beza adjetivaba "diabólica" por suponer "que cada uno podía adorar a Dios a su arbitrio". Bayle, en cambio, presenta como "un pecado escandaloso aparentar ser cristiano cuando la conciencia nos muestra que la religión china, de la que abjuramos externamente, es la mejor de todas" 22 , una idea que parece de difícil acomodo dentro del cuadro racionalista predominante. En efecto, ¿cómo hacer compatible el carácter objetivamente determinable de la verdad religiosa con esta aparente afirmación de la buena fe de un pagano que considera su religión como la mejor de todas? Dicho de otra manera, si es la recta ratio, por estar basada en la summa ratio del Dios verdadero, la única guía confiable para determinar aquello que debemos creer, ¿puede admitirse que un pagano al que se le enseña el Evangelio y su conformidad con ley natural rechace esa enseñanza para encerrarse en sus creencias tradicionales? Estas preguntas, que remiten a la distinción tradicional entre conscientia sana y conscientia fal$s a$, son marginales aquí, y algo forzadas, pero anuncian un cambio fundamental.

\footnotetext{
${ }^{20}$ Comm. Phil., I, iv, OD., II, pp. 379b.

${ }^{21}$ Sobre las concepciones calvinistas de la libertad de conciencia, además de los ya citados Rex y Laplanche, son muy instructivos los artículos de Alain Dufour, "La notion de liberté de conscience chez les Réformateurs", Olivier Millet, "Le théme de la conscience libre chez Calvin" y Mario Turchetti, "La liberté de conscience et l'autorité du Magistrat au lendemain de la Révocation", en Hans Guggisberg et al. (Eds), La liberté de conscience (XVIe-XVIle siècles). Actes de Colloque de Mulhouse et Bâle (1989), Genève, Librairie Droz, 1991.

${ }^{22}$ Comm. Phil., I, iv, OD, II, p. 379 b.
} 


\section{2. "Un camino abierto hacia el deísmo y el ateísmo".}

La segunda parte del Commentaire, como lo adelantábamos, se propone responder a las objeciones que pudieran hacerse a las nueve refutaciones anteriores. La primera objeción que Bayle examina es el argumento clásico de que no se recurre a "la violencia con el fin de molestar a las conciencias, sino para despertar a los que se rehúsan a examinar la verdad" ${ }^{23}$. La reflexión acerca de lo que significa "rehusarse a examinar la verdad", lo lleva a analizar la noción de "obstinación", vicio que los ortodoxos endilgaban a los herejes y sobre el cual justificaban el uso de la fuerza. Bayle observa al respecto que resulta imposible distinguir esa "obstinación" de la constancia, esto es, de la convicción en conciencia, y que ni siquiera el hecho de que el hipotético obstinado no consiga responder a las objeciones que se le pudieran hacer desde la ortodoxia justifica ese apelativo, "puesto que la convicción personal no siempre depende de la habilidad para defenderla" ${ }^{24}$.

El "obstinado" es aquel que se mantiene en sus propias convicciones religiosas a pesar de los argumentos contrarios; ahora bien, argumenta Bayle, la obstinación resulta siempre un cargo reversible, puesto que la evidencia es "una cualidad relativa" y nadie puede asegurar, si no es en relación con las nociones comunes $^{25}$, que lo que nos parece evidente a nosotros le debe parecer así también a los demás. Las razones de esa relatividad se presentan en el pasaje siguiente:

\footnotetext{
${ }^{23}$ Comm. Phil., II, i, OD, II, p. 393a.

${ }^{2+}$ Comm. Phil., II, i, OD, II, p. 396a. De otra manera, dice Bayle, todos los creyentes se volverían obstinados en algún momento, pues ¿quién puede presumir de que no encontrará jamás un adversario con una inteligencia más sutil o con mayor facilidad de palabras?

${ }^{25}$ Bayle concibe las "nociones comunes", sobre las cuales no podría haber desacuerdo, de una manera sumamente vaga, al menos en el Commentaire. En la primera parte (véase pp. 370a y 371b-372a), parece incluir entre ellas enunciados analíticos ("el todo es más grande que su parte"), nociones morales ("se debe preferir la virtud al vicio") y nociones del sentido común ("para preparar una tierra con vistas a una cosecha abundante se debe trabajarla"). En la segunda parte, no queda claro que las nociones morales permanezcan en la lista. puesto que Bayle sólo nombra entre las verdades que excluyen el desacuerdo "las propiedades de los números", "los primeros principios de la metafísica" y las "demostraciones de la geometria" (véase p. 437b).
} 
Esta evidencia que encontramos en ciertos objetos puede venir, o del sesgo según el cual los consideramos, o de la proporción que tienen con nuestros órganos, o de la educación, o del hábito, o de algunas otras causas; de manera que no hay consecuencia alguna de nosotros a nuestro prójimo, dado que otro hombre no ve las cosas con el mismo sesgo que las vemos nosotros, no tiene los órganos que sirven a la comprensión modificados como nosotros, no ha sido educado como nosotros, y así del resto ${ }^{26}$.

A continuación, Bayle compara el debate sobre la evidencia de las convicciones religiosas con el que se podría tener acerca de las bondades de un vino o de un cuadro, y concluye calificando como "ignorancia crasa del mundo, y principalmente del hombre, juzgar el gusto de otro por el propio".

"Sesgos", "hábitos", "educación", "gusto", estos términos con los que prácticamente se abre la Parte II del Commentaire auguran que se introducirá en ella una nueva manera de reflexionar acerca de las creencias religiosas. La luz natural hasta aquí dominante, esa razón universal "que esclarece las inteligencias y que no yerra jamás si se la consulta con atención", parece haber dado lugar ahora a otro concepto de razón, la razón postadánica, sometida indefectiblemente al cuerpo y la relatividad cultural. Se diría que Bayle, después de su viaje por las tierras del optimismo racionalista, ha recordado súbitamente que en el comienzo de la historia humana estaba el pecado y que ese acontecimiento volvía imposible "la simple contemplación de la verdad que Adán había gozado antes de su caída" ${ }^{27}$. Tal recuerdo hace que se opaque la vinculación directa de la inteligencia humana con el Verbo eterno y que la

\footnotetext{
${ }^{26}$ Comm. Phil., II, i, OD, II, p. 396b.

${ }^{27}$ Alan Ch. Kors (Atheism in France. 1650-1729, Vol. 1, New Jersey, Princeton University Press, 1991, pp. 342) recuerda la presunción filosófica que el jansenista Pierre Nicole denunciaba en los cartesianos por pensar que la razón era capaz de superar la herida del pecado original. Las palabras que citamos pertenecen justamente a Nicole.
} 
voz de la conciencia aparezca definida no por su aspecto objetivo, dictamen de la recta razón basado en la Razón suprema de Dios, sino por su aspecto subjetivo: convicción individual ligada a las objetos que desde nuestra posición histórica y religiosa nos parecen verdaderos $^{28}$. La idea no era completamente nueva para la teología calvinista, es cierto ${ }^{29}$. Pero ningún teólogo había llevado su posición hasta el extremo de comparar la convicción religiosa con el gusto subjetivo por un cuadro o un vino. Bayle sí lo hace, y da la impresión de que ese paso lo ha puesto indefectiblemente fuera del confiable seno del calvinismo malebranchiano en el que hasta entonces parecía estar moviéndose. Los capítulos siguientes ratificarán tal impresión.

Abandonando o relegando a un muy segundo plano los postulados iluministas, en efecto, Bayle de ahí en más observa al hombre como un ser moralmente débil y a la razón como una potencia que, por estar unida a un cuerpo, se mueve en el interior de una situación histórica y geográfica fortuita. En este nuevo contexto, sometida el alma a una multiplicidad de sensaciones confusas, a pasiones, opiniones y prejuicios, la conciencia "y el sentimiento interior de esta conciencia, su convicción plena y entera", es la única piedra de toque para discernir lo apropiado y adoptar la conducta conveniente $^{30}$. El polo objetivo de dicha convicción de conciencia

\footnotetext{
${ }^{28}$ Mario Turchetti, en "La liberté de conscience et l'autorité du Magistrat au lendemain de la Révocation" (ed. cit., pp. 308-310), observa que Bayle se ocupa de estas cuestiones en su Systema totius philosophiae, que escribe entre 1675 y 1680 para sus clases en la Academia de Sedán y que su posición es por entonces perfectamente ortodoxa: sólo la conscientia sana es regla legitima de la bondad moral; la conscientia falsa, en cambio, sometida como está a los prejuicios y las pasiones, no puede serlo, por más persuadida que esté.

${ }^{29}$ Walter Rex nos enseña que cincuenta años antes de que se publicara el Commentaire. en 1633, un autor importante como Jean Daillé ya habia afirmado que desobedecer a la conciencia era en sí mismo un pecado y que los motivos de la conciencia no estaban en lo que era objetivamente verdadero sino en lo que aparecía como verdadero al individuo. Véase Essays on Pierre Bayle, pp. 117-119.

${ }^{30}$ A lo largo de todo el Commentaire, Bayle mantiene que la conciencia es "la voz y la ley de Dios" y que, por lo tanto, "violar esa conciencia es esencialmente creer que se viola la ley de Dios, [...] es esencialmente un acto de odio o un acto de desprecio a Dios": no puede haber pecado mayor que tal violación. Véase Comm. Phil., I, v, I, vi, y II, viii. O. D., II, p. 379b, p. 384 b y p. 425 a. Notar que se trata primariamente de un deber de obediencia; de tal deber se deriva el derecho a actuar según las propias convicciones y el deber correlativo que tienen los otros hombres de respetar lo decidido
} 
recibe el nombre de "verdad respectiva" o " verdad putativa"; la verdad tal como cada individuo la concibe de buena fe a partir de lo que la costumbre o la educación le han transmitido. Bayle razona que Dios, siendo él mismo quien por sus inescrutables designios ha puesto al hombre ante obstáculos que impiden el conocimiento absoluto, no puede exigirle más que esa buena fe: "de tal manera que si la combinación de circunstancias nos impide encontrar la verdad absoluta y nos lleva a descubrir el gusto de la verdad en un objeto que sea falso, esa verdad putativa y respectiva debe ocupar para nosotros el sitio de la verdad real" ${ }^{\prime 2}$. Como se comprenderá, esta idea implica la recusación de la necesaria culpabilidad del error o de la ignorancia, doctrina de san Agustín que, renovada por Arnauld, adjudicaba todos los errores a la corrupción del corazón y encontraba allí motivo para castigar a los herejes ${ }^{32}$.

(Puede consultarse, al respecto, John Kilkullen, Sincerity and Truth. Essays on Arnauld, Bayle, and Toleration, Oxford, Clarendon Press, 1988, cap. II).

${ }^{31}$ Comm. Phil., II, x, OD, II, pp. 44 la-b. Véase también pp. 437a. Rex (Essays on Pierre Bayle, p. 175) considera que cuando el Commentaire compara las convicciones religiosas con los gustos subjetivos por un cuadro o un vino (véase supra, pp. 9) "resulta como si Bayle, atraído por la tentación de las paradojas escépticas, perdiera momentáneamente el control en la dirección del argumento". Lo menos que puede decirse al respecto es que esa momentánea "pérdida de control" se repite en otras oportunidades. Obsérvese si no el siguiente pasaje: "No importa que esta conciencia muestre a un hombre determinado objeto como verdadero y a otro como falso, ¿no sucede lo mismo acaso con la vida corporal? ¿Acaso el gusto de uno no muestra como buena la vianda que el gusto de otro muestra como mala? ¿Impide esta diversidad que cada uno encuentre su alimento? ¿No alcanza acaso con que los sentidos nos muestren la conveniencia que los objetos tienen con nosotros, sin que sea necesario que sepamos sus cualidades absolutas? De la misma manera, alcanza con que la conciencia de cada uno le muestre, no lo que los objetos son en sí mismos. sino su naturaleza respectiva, su verdad putativa. Cada uno discernirá por este medio su alimento. Será preciso que trate de discernir lo mejor y ponga en eso todos sus cuidados; pero si siéndole presentado [lo mejor], su conciencia no se acomoda a ello, y se descubre sin gusto en ese sentido y con un gran gusto por otra cosa, magnífico, deberá optar por esta segunda opción."(Comm. Phil., II, x, OD, p. 441 a)

${ }^{32}$ No es el enceguecimiento voluntario o el odio lo que lleva a interpretar de tal o cual manera las Escrituras, dice Bayle. "Lo que se puede decir, más razonable, es que los prejuicios de la educación impiden encontrar en la Escritura lo que está allí. Pero como resulta verdadero en general para todos los hombres del mundo, excepto algunos pocos que cambian por razonamiento, deberle a la educación el hecho de ser de una Religión y no de otra (puesto que si hubiéramos nacido en la China seríamos todos Chinos, y si los Chinos hubieran nacido en Inglaterra serían todos Cristianos, y si se enviaran a una isla deshabitada un hombre y una mujer fuertemente convencidos, como si fuera un dogma necesario para la salvación, de que en el Cielo el todo no es más grande que su parte, al cabo de doscientos o trescientos años tal cosa sería un artículo de fe en la Religión de todo el país), como, digo, eso resulta verdadero, hablando en general, no sería más que un reproche vago que todos los hombres se harian reciprocamente [...]" (Comm. Phil., II, x, OD, II, p. 440b). El pasaje entre parénte- 
Conceptos heterodoxos, más cercanos al marginal Sébastien Castellion que a los padres de la Reforma ${ }^{33}$. Desde ellos, Bayle construirá otro dispositivo para deslegitimar la coacción por motivos religiosos. Utilizando argumentos escépticos, relativiza nociones caras al discurso violento -"herejía"34, "blasfemia"35 -, coloca la conciencia errónea en un pie de igualdad con la conciencia esclare$\operatorname{cida}^{36}$ y afirma que el criterio para distinguir el vicio de la virtud, el criterio que Dios tendrá finalmente en cuenta para su juicio, es puramente formal: si la acción ha sido ejecutada conforme a las indicaciones de la verdad putativa (después de un examen honesto) será justa, si ha sido ejecutada despreciando tales indicaciones será pecado y merecerá castigo ${ }^{37}$. Afianzando este criterio formal por un

sis es particularmente digno de atención, puesto que nos llevaría a pensar que no hay dogma, por imposible que parezca, que la religión no pueda enseñar como palabra santa. Sobre las diferencias entre Bayle y Arnauld a propósito del pecado como fuente del error religioso, puede verse el estudio ya citado de John Kilkullen, Sincerity and Truth. Essays on Bayle, Arnauld, an Toleration.

${ }^{33}$ A partir de la muerte de Miguel Servet en 1553, el calvinista Sébastien Castellion sostuvo durante diez años una agria polémica con Calvino y Teodoro de Beza en torno a la condena que merecían los errores religiosos. Castellion consideraba que las llamadas "herejías" eran diferencias de opinión provocadas por la oscuridad de las Escrituras y que en ningún caso debían ser castigadas con la pena capital. Al respecto, véase J. Lecrer, Historia de la tolerancia en el siglo de la Reforma, trad. de A. Molina Meliá, Alcoy, Ed. Marfil, tomo I, libro IV, Cap. II.

34 "[...] como la fe no nos da otras señales de ortodoxia que el sentimiento interior y la convicción de la conciencia, señales que se encuentran en los hombres más herejes, se sigue que en último análisis nuestra creencia, sea ortodoxa o heterodoxa, radica en que sentimos y en que nos parece que esto o aquello es verdadero. De donde concluyo que Dios no exige ni del ortodoxo ni del hereje una certeza adquirida mediante un examen y una discusión científica, y en consecuencia se conforma con que uno y otro ame lo que le parezca verdadero." (Comm. Phil., II, x, OD, II, p. 439b). Cf. Ibidem, p. $438 \mathrm{~b}-439 \mathrm{a}$.

${ }^{35}$ Los partidarios de la coacción, dice Bayle, justifican su opinión diciendo que el hereje "pronuncia blasfemias insoportables y deshonra la majestad de Dios de la manera más sacrílega". En realidad, se trata sólo de "otras maneras, diferentes a las nuestras, de hablar honorablemente de Dios. [...] No hay nada que decir contra él sino que debería informarse mejor de las maneras de hablar de Dios que parezcan honorables en la Corte celestial. Pero si responde que se ha informado tanto como ha podido, y que sólo después de todas las indagaciones posibles se ha atenido a tales maneras de honrar a Dios [...]; si les responde eso, digo, ¿no deberían cerrar la boca, a menos que lo convenzan que habla falsamente, lo cual no es posible más que para Dios [...]?" (Comm. Phil., II. vi, OD., II, pp. 417 b-418 a). Cf., Ibidem, II, vii, p. 421 a.

36 "[T]odo lo que la conciencia bien esclarecida nos permite hacer para el avance de la verdad, la conciencia errónea nos lo permite para lo que creemos la verdad." (Comm. Phil. II, viii, OD, p. 422b) 37 "[...] el soberano Juez del mundo, el escrutador de riñones y corazones, no puede hacer diferencia entre dos actos de la voluntad humana, completamente semejantes en su entidad física, aun cuando por accidente su objeto no sea realmente el mismo; puesto que alcanza con que sea objetivamente el 
lado, y ampliando por el otro los casos en que cabe aplicar la disculpa de "ignorancia invencible" ${ }^{38}$, exige entonces la implantación de una sociedad en la que todas las creencias, incluyendo a los $\operatorname{ateos}^{39}$, puedan vivir libremente sus convicciones sin otros límites que la tranquilidad pública y la seguridad de la soberanía ${ }^{40}$. En una época en que la lucha contra el socinianismo era feroz ${ }^{41}$, en que el odio entre las confesiones mayoritarias estaba lejos de apaciguarse, en que incluso un liberal como John Locke expulsaba de su tolerante sociedad a católicos y ateos ${ }^{42}$, se comprende que esta propuesta

mismo, quiero decir, que así se lo parezca a las dos voluntades que ejecutan los actos. [...] la bajeza de una acción ante el Tribunal de la justicia divina no se mide por la cualidad real de los sujetos a los que tiende sino por las cualidades objetivas, es decir, que Dios no considera más que el acto de la voluntad." (Comm. Phil., II, ix, OD, II, p. 428 a-b) Para un análisis agudo de esta cuestión, véase Jean-Pierre Jossua, "Pierre Bayle, précurseur de théologies modernes de la liberté religieuse", en Révue de Sciences religieuses, 2, abril 1965, especialmente pp. 140-146.

${ }^{38}$ Cf. Comm. Phil., II, x, OD, II, p. 442 a-b. Se encontrará un buen resumen de la posición de Bayle al respecto en la Addition aux pensées diverses sur la comète. $v$, OD, III, p. 180.

${ }^{39}$ Bayle admite "en la república", explícitamente, a socinianos, judíos y turcos (Cf. Comm. Phil., II, vii, OD, II, pp. 419b-420 a). Incluye también a los católicos, con ciertas restricciones (véase ibidem, II. v, p. $412 \mathrm{~b}$ ), y a los paganos, de forma implícita (véase ibidem, II, ix, p. 429b). En relación con los ateos, declara en el Commentaire que el magistrado puede prohibirles hacer proselitismo y que ellos, por su parte, al no creer en Dios, no podrían oponerse a tal medida alegando motivos de conciencia (véase ibidem, II, ix, p. 431 a). En ningún momento se dice, sin embargo, que los ateos deban ser expulsados de la sociedad u obligados a convertirse, y muchos de los mejores intérpretes (Labrousse. Rex, Jossua, Mori, Paganini) coinciden en que la severidad para con los ateos es una concesión hecha por el Commentaire a los lectores de su tiempo.

${ }^{+0}$ Además de la tranquilidad pública y la seguridad de la soberanía, Bayle indica un tercer límite en relación con la libertad de opinión: la sinceridad de los que la sostengan. Por este motivo afirma que los herejes que sean conscientes de su error no deben ser tolerados y merecen la muerte "si se sabe con certeza que predican el error y la herejía a sabiendas, conociéndolos como tales, por malicia a intereses humanos" (Comm. Phil., II, iv, OD. II, p. 409a).

${ }^{+1}$ La tolerancia de los socinianos podría ser el objetivo central del Commentaire (así lo sugiere una carta de Bayle a J. Lenfant del 3 de febrero de 1687, OD, IV, p. 629b). Recordemos que la ley sobre la tolerancia -Toleration Act- aprobada por el parlamente inglés después de la Revolución Gloriosa de 1688, que entronizó a Guillermo de Orange en el poder, exigía de los ciudadanos ingleses una profesión de fe en el Dios Uno y Trino, esto es, les prohibía adherir al antitrinitarismo de los seguidores de Socin. Véase al respecto, Bernard Cottret, "La tolérance et la liberté de conscience à l'épreuve", Hans Guggisberg et al. (Eds), La liberté de conscience (XVIe-XVIIe siècles), ed. cit., pp. 274-275.

${ }^{+2}$ Véase J. Locke, Carta sobre la tolerancia, ed. de P. Bravo Gala. Madrid, Tecnos, 1991, pp. 52-59. Locke publica anónimamente esta carta en 1689. Las razones que alega para excluir a católicos y ateos es que sus creencias (los católicos por colocar la autoridad del papa por encima de la de los príncipes, los ateos porque no tienen por quién jurar) los hacen incapaces de respetar el contrato que instituye una sociedad. Puede consultarse al respecto el artículo de Cottret citado en la nota anterior (p. 286). 
haya sorprendido a la República de las Letras y que las plumas más reputadas del refuge holandés la hayan calificado como "teología libertina", "pirronismo", "indiferentismo", "destructora del fundamento de la Reforma" o "camino abierto hacia el deísmo y el ateísmo" ${ }^{43}$.

\section{El arte de ponerse en duda.}

Calificábamos al Commentaire philosophique como un "compuesto enigmático". Los dos parágrafos anteriores procuraron justificar esa apreciación. Parece haber en él dos proyectos, uno próximo a Malebranche y a la École de Saumur y otro de tendencia escéptica, cuya conciliación se nos escapa. Y así como decíamos que resultaba difícil discutir la valoración del Commentaire como "el más cristiano y el más racionalista" de los escritos de Bayle si no avanzábamos más allá de la Parte I, de la misma manera podríamos decir que, ateniéndonos a lo dicho en la Parte II, no les faltaba motivos a quienes veían en el escrito un intento por derribar las bases puramente cristianas de la sociedad.

No sólo eso. El Commentaire, una ofensiva contra la coacción religiosa, incluye sin embargo pasajes que peligrosamente se acercan a declarar esa coacción como una consecuencia inevitable de los principios concebidos para rebatirla. Nos referimos, claro está, a las reflexiones contenidas en el capítulo IX de la segunda Parte, donde Bayle acepta que su concepto de la verdad "putativa"

\footnotetext{
${ }^{43}$ Estos, y otros epítetos, fueron utilizados por Pierre Jurieu y Jacques Saurin, teólogos calvinistas refugiados en Holanda, quienes reaccionaron ante el Commentaire publicando Des Droits de deux Souverains en matière de Religion, la Conscience et le Prince. Pour détruire le dogme de l'indifference des Religions et de la tolerance Universelle. Contre un libre intitulé Commentaire philosophique sur ces paroles de la Parabole "Contrain-les d'entrer" (Jurieu) y Réflexions sur les droits de la conscience. Oú l'on fait voir la différence entre les droits de la Conscience éclairée et ceux de la Conscience errante. On refute le Commentaire Philosophique, et le livre intitulé Droits de deux Souverains; Et on marque les justes bornes de la Tolerance Civile en matiere de Religion (Saurin). Se encontrarán buenos resúmenes de las críticas de Jurieu y Saurin en el artículo de Mario Turchetti, "La liberté de conscience et l'autorité du magistrat au lendemain de la Révocation", en La liberté de conscience (XVIe-XVIIe siècles), ed. cit., pp. 314-330.
} 
como fuente de obligación moral podría llevar a pensar que "todo hombre que se crea obligado en conciencia a perseguir estaría obligado a hacerlo y haría mal si no persiguiera" ${ }^{44}$ : una paradoja que amenaza con echar por tierra todos los argumentos esgrimidos hasta allí a favor de la tolerancia y que Bayle, teniendo en cuenta el contexto relativista, ya no puede solucionar apelando a la claridad de la Escritura y de la luz natural. Los magistrados civiles podrán tener pleno derecho a castigar esas persecuciones como atentados contra la tranquilidad pública ${ }^{45}$, pero el hecho cierto es que la bacteria escéptica parece no haber dejado principios religiosos o morales suficientemente fuertes como para impugnarlas.

Los intérpretes que notaron estos problemas han reaccionado de maneras diversas. John Kilcullen, por ejemplo, considera que no hay contradicciones serias entre las dos partes del Commentaire y que el juicio absoluto de la conciencia que se afirma en la Parte II es un complemento, no un reemplazo, de la ley natural que domina en la primera Parte ${ }^{46}$. Walter Rex es menos optimista. Cree que en algunos pasajes de la Parte II Bayle parece estar diciendo "exactamente lo opuesto a lo se que había dicho antes" y que tal contradicción sólo podría explicarse por su amor a las paradojas, si es que no se quiere recurrir a la perversidad ${ }^{47}$. Gianluca Mori está sustancialmente de acuerdo con Rex. Coincide en que hay una mutación importante en el interior del Commentaire, sobre todo en relación

\footnotetext{
${ }^{+4}$ Comm. Phil., II, ix, OD, II, p. 430b.

${ }^{45}$ Bayle sostiene, en general, que al magistrado no le conciernen las cuestiones referidas a la conciencia o a la religión y que su única función es proteger la paz y la seguridad de la sociedad. Por eso puede castigar a los que persiguen o asesinan según los instintos de su conciencia ateniéndose exclusivamente a sus acciones, sin "desentrañar esas ocasiones raras y singulares en las que la conciencia cae en la ilusión" (Comm. Phil.. II, ix, OD, II, p. 433b).

${ }^{+6}$ Kilcullen, Sincerity and Truth. Essays on Bayle, Arnauld, and Toleration, pp. 77-78 y 103-104. En relación con el reconocimiento de la obligación de perseguir que tendrían aquellos que así lo creyeran de buena fe, Kilcullen considera que no destruye el alegato a favor de la tolerancia y que se limita a constatar la colisión de dos deberes morales: el que tienen los individuos de llevar a cabo una acción -aun equivocada- cuando la conciencia así lo indica y el que tiene el magistrado de impedirlo cuando amenaza los derechos ajenos. Véase ibidem, pp. 173-174.

47 "Parece casi perverso por parte de Bayle que tantos de sus temas del comienzo reaparezcan en este penúltimo capítulo y que él parezca estar diciendo exactamente lo opuesto a lo que había dicho antes." Véase W. Rex, Essays on Pierre Bayle and Religious Controversy, pp. 180-184.
} 
con el concepto de conciencia, y que, por ese motivo, esta obra no logra construir una fundamentación coherente de la tolerancia ${ }^{48}$.

Como es visible, nuestra interpretación se mantiene cerca de las que ofrecen Mori y Rex. Es en buena medida deudora de ellas, en realidad, sobre todo de la de Walter Rex, cuyo estudio significó una confirmación decisiva para las sospechas que nos habían asaltado en la primera lectura del Commentaire. No pretendemos aportar aquí nada de gran importancia, por lo tanto, en lo que se refiere a la comprobación puntual de tensiones, apuros e incluso contradicciones que existen entre las dos partes que hemos presentado: la página 184 de Essays on Pierre Bayle and Religious Controversy es casi exhaustiva al respecto. Hay un punto, de todas maneras, que Rex no toma en suficiente consideración; tampoco Mori, ni Kilcullen: todos ellos parecen suponer que Bayle elabora en el Commentaire una teoría fundamentadora de la tolerancia, y que es esa teoría la que encierra en su interior conflictos más o menos difíciles de superar. Queremos concluir el presente artículo indicando dos pasajes del escrito que apuntan en otra dirección y que podrían ayudar a interpretarlo.

El primero de ellos aparece muy pronto, en el "dicurso preliminar", donde Bayle indica que su objetivo principal es "desorientar un poco a los señores convertidores, esto es, sacarlos de sus lugares comunes y proponerles dificultades acerca de las cuales no hayan tenido tiempo de inventar escapatorias" 49 . Si nos atenemos a esta declaración, el Commentaire se plantearía como una obra crítica antes que constructiva, destinada menos a organizar una teoría general de la tolerancia que a sacar a luz los sofismas o las inconsecuencias de las teorías que la niegan. Su meta es única, sí: mostrar la falsedad de los razonamientos o la inmoralidad de los su-

\footnotetext{
${ }^{48}$ Véase Mori, G.. Introduzione a Bayle, pp. 64-68. Para Mori, el penúltimo capítulo de la Parte II evidencia "el fracaso sustancial del intento bayleano por fundar la tolerancia sobre los derechos morales de la conciencia errónea".

${ }^{49}$ Comm. Phil., discours préliminaire, OD, II, p. 357b.
} 
puestos que apoyan la persecución; pero para conseguirla no es imprescindible elaborar una única cadena de réplicas. Es más, la diversidad de argumentos podría hacer comprender a los "señores convertidores" que son también diversos sus enemigos y que la impugnación de uno de ellos no significa que los demás deban considerarse rebatidos. He aquí una conjetura apoyada por la independencia que se observa entre los nueve argumentos de la Parte I: puede que el carácter absoluto de la ley natural sea imprescindible para demostrar que la persecución "derriba los límites que separan la justicia de la injusticia y confunde el vicio con la virtud para ruina universal de las sociedades", pero no parece que el mismo sea necesario para probar que si se acepta la persecución como un mandato revelado, los infieles tendrán "un pretexto muy plausible y muy razonable para no dejar entrar a ningún cristiano en sus países y para expulsarlos de todos los lugares en que los encuentren" ${ }^{20}$. No es una infracción moral la que llevaría a los infieles a tomar tal decisión, sino una infracción política que puede convivir perfectamente con una inclinación relativista y escéptica. Algo parecido sucede con la sexta refutación del sentido literal. Si se aceptara ese sentido, dice Bayle, se privaría a la religión cristiana de "un argumento poderoso del cual ésta se sirve para atacar a los mahometanos"; un argumento "poderoso", en efecto, pero apoyado en razones tácticas antes que estrictamente morales. ${ }^{51}$

Las pruebas en contra del sentido literal de la Parte I, por lo tanto, pueden entenderse como razonamientos independientes, argumentaciones particulares elaboradas para situaciones específicas y atenidas más a las reglas de la retórica que a las de la lógica for$\mathrm{mal}^{52}$. Tomadas una a una, además, podrían ser sostenidas desde

\footnotetext{
${ }^{50}$ Véase Comm. Phil., I, iv y v, OD, II, pp. 374b y 377a. No estamos de acuerdo con Rex en este sentido, puesto que para él "todas estas nueve pruebas giran alrededor de un solo tema y conducen a la misma conclusión, a saber, que una interpretación literal del pasaje 'oblígalos a entrar' es contraria a las leyes fundamentales de la ética y, por lo tanto, falsa" (Essays on Pierre Bayle, p. 166).

${ }^{5 l}$ Véase Comm. Phil., I, vii, OD, II, p. 386b.

52 Tomamos esta distinción entre "retórica" y "lógica formal" de Stephen Toulmin. Para Toulmin, la pregunta retórica es "¿Quién dirigió a quién este argumento, en qué foro y usando qué ejemplos?"
} 
posiciones filosóficas diversas, y hasta rivales, unidas circunstancialmente en su voluntad de impugnar el uso de la violencia. Bayle parece sugerir y promover esta última posibilidad cuando en el prefacio del Suplement du Commentaire philosophique dice que quienes tradujeron su obra del inglés "se han divertido mezclando en ella cosas tan pronto dependientes de un sistema como de otro, imitando algunas veces la manera de pensar de ciertos autores y no el estilo, mientras otras veces imitaban estilo pero no maneras de pensar, haciendo así varios disparates que han llevado, según ellos, a que mi Commentaire fuera adjudicado por los lectores a gente muy diferente" ${ }^{53}$. Este pasaje asombroso, que curiosamente no ha sido tenido en cuenta por los mejores intérpretes, revelaría que Bayle utilizó conscientemente en su obra ideas provenientes de doctrinas distintas y que lo hizo como estrategia -fallida- para ocultarse como autor de la misma. He allí una punta para explicar las dificuitades relacionadas con la coherencia interna: las voces que componen el Commentaire son diversas y quieren mantenerse en esa diversidad. Buscar acomodarlas en un sistema único implica ejercer sobre ellas una presión que su mismo "vocero" desaconseja.

Ahora bien, de todas esas voces, ¿cuál, si alguna, debería ser adjudicada al propio Pierre Bayle? Juzgando el escrito a la luz de ciertas obras anteriores y de todas las que lo siguieron, creemos que la respuesta no es difícil. Podríamos formularla así: Bayle, a nuestro juicio, no es el celoso promotor del calvinismo malebranchiano que impera en la primera Parte, sí es el atribulado promotor de los derechos de la conciencia errónea que se impone con fuerza creciente en la segunda mitad del escrito. Como justificación de la

\footnotetext{
Esa pregunta, frecuente entre los escritores de los siglos XV y XVI, fue descartada a su juicio por la tradición filosófica que se inicia con Descartes y reemplazada por pruebas de valor universal: "Después de 1630, la tradición de la Filosofía Moderna en Europa Occidental se concentró en análisis formales de cadenas de afirmaciones escritas antes que en los méritos y defectos circunstanciales de expresiones persuasivas. [...] Dentro de esta tradición, la lógica formal estaba incluida, la retórica excluida." (S. Toulmin, Cosmopolis. The Hidden Agenda of Modernity, Chicago, The University of Chicago Press, 1990, p. 31).

${ }^{53}$ Suplement du Commentaire philosophique, prefacio, OD, II, p. 498b.
} 
primera apreciación, baste saber que ya desde comienzos de 1685 , un año y medio antes de la publicación del Commentaire, Bayle había adoptado una posición francamente crítica frente a Malebranche $^{54}$ y que nunca adhirió, ni manifestó simpatía, por algunas de las "visiones" del padre del Oratorio que cumplen un papel fundamental en los primeros capítulos ${ }^{55}$. Como justificación de la segunda apreciación, ateniéndonos exclusivamente a obras anteriores al Commentaire, se podrían citar pasajes de la Critique générale de l'Histoire de Calvinisme de M. Maimbourg ${ }^{56}$ o todo el capítulo IX de las Nouvelles lettres critiques donde precisamente se habla "de la conciencia errónea y de los errores de buena fe" y Bayle sostiene con firmeza que la distinción absoluta entre verdad y error se disipa apenas se desciende de las precisiones abstractas de la lógica para atender a la consideración particular, "en relación con cada persona" ${ }^{57}$. Estos textos, así como otros innumerables del Dictionnaire historique et critique, socavan la intolerancia social desde la posición escéptica y relativista que se dibuja en la segunda mitad del Commentaire y se apoyan sobre el mismo fundamento religioso: la debilidad moral e intelectual de la condición postadánica.

\footnotetext{
${ }^{54}$ Gianluca Mori cita una carta a Jean Le Clerc de abril de 1685 en la que Bayle felicita al teólogo arminiano por las "excelentes objeciones" que había hecho a la teoría malebranchiana, pidiéndole, no obstante, que mantuviera en secreto esa felicitación (Jean Le Clerc, Epistolario, Vol. I, Firenze, 1987, p. 318. Citado por G. Mori, Introduzione a Bayle, pp. 54-55). Mori considera que Bayle no se atrevía por esa fecha a mostrar abiertamente sus diferencias con Malebranche; en las Nouvelles de la République des Lettres de agosto de 1685, sin embargo, Bayle apunta que ciertos aspectos de la teoria malebranchiana, sobre todo la negativa a aceptar voluntades particulares en Dios, resultan difíciles de sostener por su oposición a la palabra revelada (véase NRL, agosto de 1685, art. iii, OD, I, p. 437a).

${ }^{55} \mathrm{La}$ teoría de que vemos las ideas en Dios, por ejemplo, resultaba ininteligible para Bayle, quien desde sus primeros escritos entendió las ideas como "modalidades del alma" (véase Objections à Poiret, OD, IV, p. 153b). Bayle lo dice con claridad en una carta a Desmaizeaux de octubre de 1705: "He recorrido el nuevo libro del padre Malebranche contra el Sr. Arnauld y menos que nunca pude entender su pretensión de que las ideas, por medio de las cuales conocemos los objetos, están en Dios y no en nuestra alma. Hay allí un malentendido; se trata, me parece. de equívocos perennes" (OD, IV, p. 866a). Respecto del término "visiones", Bayle lo utiliza para referirse a las hipótesis de Malebranche en el panfleto contra Luis XIV titulado Ce que c'est que la France toute catholique sous le règne de Louis le Grand. Todo este escrito es una sardónica comprobación de la "verdad" del malebranchismo y fue publicado, recordemos, seis meses antes que el Commentaire.

${ }^{56}$ Véase, por ejemplos, Critique générale, II, $\mathrm{xx}, \mathrm{y}$ III, xxi, OD, II, pp. 87b y 94a

${ }^{57}$ Véase Nouvelles lettres, IX, OD, II, pp. 218-220b.
} 
Ahora bien, se dirá, la diversidad de voces del Commentaire no elimina el gran escollo que representa el capítulo 9 de la Parte II; peor aún, lo agrava, puesto que es precisamente "la voz escépti$\mathrm{ca}^{\prime}$ la que termina recurriendo al poder heterónomo del Estado como única defensa subsistente contra los perseguidores a conciencia, poniendo así en riesgo la causa contra la intolerancia en su conjunto. Es cierto. Bayle, por lo demás, tiene perfecta conciencia del peligro que encierran esas consecuencias: son trampas, dice, que tiende la misma razón a quienes quieren obedecerle ciegamente ${ }^{58}$. Confía en que los argumentos que ha aportado esclarecerán "en aquellos que los examinen con sinceridad [...] los errores de conciencia en que podrían estar en cuanto a la persecución"59, pero reconoce que la razón es incapaz de resolver lógicamente el problema. Para enfrentarlo, e intentar superarlo, sugiere cambiar de terreno: abandonar el dominio de la lógica abstracta y atender a la situación particular en que se plantee. En el caso singular se podrá eventualmente sacar a luz la mala fe de los perseguidores o intentar persuadirlos de que han interpretado mal el Evangelio. "La respuesta de Bayle es insatisfactoria", dice Rex; "señala el fracaso sustancial de Bayle por fundar la tolerancia sobre los derechos de la conciencia errónea", comenta Mori. Puede ser. Pero quizás el juicio no sea tan desfavorable si recordamos con Aristóteles que la ética no es una ciencia exacta y excluye de su discurso una absoluta certeza,

\footnotetext{
${ }^{58}$ Lo dice en forma explícita: "No se puede negar que la condición del hombre está rodeada, entre otras mil imperfecciones, de ésta, que casi no conoce la verdad si no es imperfectamente, puesto que si logra probar una cosa mediante razones a priori, claras y demostrativas, muy pronto, como por una especie de aguafiestas, se ve abrumado por las consecuencias absurdas, o por lo menos muy difíciles, que parecen nacer de lo que creyó demostrar. Y si tuvo la suerte de no verse agobiado por las reducciones ad absurdum, quiero decir, por los absurdos que emanan de su opinión, sufre por otra parte la mortificación de no tener más que ideas confusas y pruebas débiles para lo que sostiene. Los que defienden la divisibilidad de la materia al infinito o los átomos de Epicuro sabrán qué decir. Tengo bastante buena fe para reconocer que, si mi opinión tiene alguna debilidad, es del lado de las consecuencias. Las pruebas directas que la apoyan son maravillosas, los resultados de la opinión opuesta son monstruosos; hasta ahí va bien. Pero cuando se observan los resultados de mi hipótesis, la cosa no va tan bien. Se diría que para humillar nuestra inteligencia, Dios quiere que la misma encuentre no fácilmente donde apoyar el pie, y que descubra trampas de cualquier lado que se vuelva" (Comm. Phil., II, 6, OD, II, p. 415a-b).

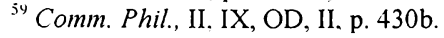


o, en palabras de Bayle, "que no hay que exigir a un hombre que escribe reflexiones sobre lo que pasa en la sociedad civil la misma exactitud que a un filósofo que investiga las verdades naturales" 60 .

\section{Resumen}

El Commentarie philosophique sur ces paroles de Jésus-Christ 'Contrain-les d'entrer' publicado en 1686 por el calvinista francés Pierre Bayle constituye uno de los capítulos más interesantes y menos conocidos en la elaboración moderna del concepto de tolerancia civil. En este artículo se reconstruye el itinerario desarrollado por Bayle en esa obra y se pasa revista a las señales de inconsistencia teórica que se han detectado en la misma. En principio, estamos de acuerdo con Walter Rex y Gianluca Mori en que los criterios racionalistas presentados en la Parte I del escrito resultan difíciles de conciliar con los argumentos escépticos que dominan en la Parte II. A nuestro juicio, sin embargo, estos y otros intérpretes comparten un supuesto no evidente: que en el Commentaire Bayle intentó elaborar una teoría de la tolerancia. Si se prestan atención a algunos pasajes de la obra, en cambio, la empresa bayleana aparece más bien como una recopilación de argumentos contrarios a la intolerancia religiosa que no requiere necesariamente de una articulación interna. Desde esta perspectiva, nos parece, las inconsistencias no resultan insalvables.

\section{Abstract}

The Commentaire philosophique sur ces paroles de Jesus-Christ 'Contrain-les d'entrer', that the French Calvinist Pierre Bayle wrote in 1686 is a particularly important book in the built-up of the concept of civil toleration on Modern Philosophy. In this article we reconstruct the principal arguments of the work and review some problems of incoherence detected. We agree with Walter Rex and

${ }^{611}$ Nouvelles lettres, XII, OD, II, p. 244b. 
Gianluca Mori on their rationalist criteria presented where they express that is difficult to conciliate in Part I with the skeptical reasoning that dominates in Part II, but it must be noted that these exegetes, and many others, have in common a non-obvious assumption: that Pierre Bayle wrote the Commentaire philosophique to present a unified theory on toleration. If we examine some passages of the book it could be seen, whereas, that the baylean design shows itself as a compilation of arguments against religious intolerance, a compilation that is not internally required to be articulated. From this point of view, we think that the problems of coherence could be saved. 